\section{A morte que salva vidas: complexidades do cuidado médico ao paciente com suspeita de morte encefálica}

\author{
Deaths that save lives: the complexities of \\ medical care for patients with suspected \\ brain death
}

\section{La muerte que salva vidas: complejidades del cuidado médico a pacientes con sospecha de muerte encefálica}

\section{Resumo}

O objetivo do presente trabalho é compreender como os médicos do maior pronto-atendimento de uma metrópole brasileira orientam o cuidado aos pacientes graves com suspeita de morte encefálica e potenciais doadores de órgãos. Trata-se de uma etnografia, desenvolvida em um hospital de pronto-socorro, referência em trauma na América Latina, situado no hipercentro da cidade de Belo Horizonte, Minas Gerais. A instituição, de modo pioneiro no Brasil, conta com um setor específico para onde são encaminhados os pacientes com suspeita de morte encefálica. O trabalho de campo foi realizado durante nove meses, baseado em observações empíricas e entrevistas junto a 43 médicos plantonistas - 25 homens e 18 mulheres, entre 28 e 69 anos. A análise dos dados foi orientada pelo modelo de "signos, significados e ações". À etnografia, emergiu o processo de cuidado médico ao paciente em suspeita de morte encefálica que contempla: terapia intensiva; realização do protocolo e comunicação do fato à família do paciente. Nesse último caso, a interlocução perpassa as controvérsias no conceito de morte encefálica, o contexto sociocultural e o contexto do pronto-atendimento. Ficou claro que esse processo de cuidado médico ultrapassa questões meramente normativas e adentra uma complexidade de elementos, sobretudo o papel do profissional como mediador de uma miríade de elementos e tensões imbricados. Entre a constatação e a comunicação da morte encefálica emergem percepções ambivalentes dos médicos e dos familiares. O estudo evidenciou que a tênue definição do que seja a vida e a morte tangencia toda a atuação médica, tendo implicações diretas no cuidado ao paciente/potencial doador e aos familiares.

Morte Encefálica; Atitude Frente à Morte; Relações Profissional-Família; Medicina de Emergência; Assistência à Saúde
Janaina de Souza Aredes 1 Josélia Oliveira Araújo Firmo 1 Karla Cristina Giacomin 1,2

doi: $10.1590 / 0102-311 \times 00061718$

\author{
Correspondência \\ K. C. Giacomin \\ Secretaria Municipal de Saúde. \\ Av. Afonso Pena 2336, Belo Horizonte, MG 30130-007, Brasil. \\ kcgiacomin@hotmail.com \\ 1 Instituto René Rachou, Fundação Oswaldo Cruz, \\ Belo Horizonte, Brasil. \\ 2 Secretaria Municipal de Saúde, Belo Horizonte, Brasil.
}




\section{Introdução}

Doenças provocadas por causas externas, especialmente oriundas de trauma, assumem expressiva relevância no âmbito das internações hospitalares no Sistema Único de Saúde (SUS) 1 . O aumento da violência urbana 2 repercute na morbimortalidade da população brasileira e configura grave problema de saúde pública ${ }^{1}$. Somam-se ao trauma, as doenças crônicas não transmissíveis que também concorrem para um número crescente de hospitalizações na urgência 3 .

Nesse contexto, para evitar a morte, desfecho que contraria e desafia os ditames biomédicos, adotam-se diferentes dispositivos médicos e institucionais a serviço da manutenção da vida 4 . Nesse sentido, o Serviço de Atendimento Móvel de Urgência (SAMU) e os Centros de Terapia Intensiva (CTI) assumem um importante papel: o primeiro assegura maior agilidade no processo de atendimento 5 , e os segundos oferecem condições para a sustentação da vida 6,7,8.

O cuidado médico pré- 5 e per-hospitalar 6,7 tem postergado a possibilidade da morte para o hospital 7 , incluindo a morte encefálica, cujas causas mais frequentes são o traumatismo cranioencefálico e o acidente vascular encefálico ${ }^{9}$. Todavia essas condições graves permitem a preservação da vida de outras pessoas por meio da doação de órgãos 10 .

Assume-se cuidado médico como um modo de reconstruir a atenção integral à saúde dos indivíduos, com base nos problemas e tensões identificados na prática profissional. Para tanto, sua compreensão deve estar relacionada ao encontro alteritário de quem cuida e de quem é cuidado, resultante das experiências de ambos 11 .

$\mathrm{Na}$ literatura internacional, estudos sobre o cuidado médico ao paciente em suspeita de morte encefálica focam no envolvimento da família neste processo, sobretudo durante a realização do protocolo de morte encefálica 12,13; nos desafios enfrentados pelos médicos durante a abordagem sobre a doação de órgãos 14,15; e nas próprias dificuldades destes profissionais referentes ao conceito de morte encefálica 16,17 .

No Brasil, de forma distinta, os estudos privilegiam, especialmente, a perspectiva do enfermeiro $6,8,18$, fatores relacionados à não-doação ${ }^{19}$, a legislação sobre a doação de órgãos 20 e diretrizes para avaliação e validação do potencial doador 10. Poucas pesquisas contemplam as complexidades do processo de diagnóstico de morte encefálica na perspectiva do médico 9,21.

Assim, o presente trabalho objetiva compreender como os profissionais médicos do maior prontoatendimento de uma metrópole brasileira - referência na América Latina - orientam o cuidado aos pacientes graves com suspeita de morte encefálica.

\section{Metodologia}

Esta pesquisa parte de uma abordagem antropológica hermenêutica 22 , na qual se enfatiza o significado que os grupos sociais atribuem a determinados fenômenos, com base em um processo de significação imbricado junto às perspectivas individual e coletiva 23

No âmbito da Saúde Coletiva, essa orientação ancorada ao método etnográfico, contribui na compreensão do processo saúde/doença, dos valores e das atitudes de profissionais e pacientes em diferentes contextos de cuidado 24 .

\section{Área e população de estudo}

Este trabalho compõe um estudo etnográfico maior iniciado em 2012, realizado por uma antropóloga no contexto de um dos maiores serviços públicos de pronto-atendimento ao politrauma e a queimados da América Latina, situado no hipercentro de Belo Horizonte, capital de Minas Gerais, estado brasileiro que tem a maior malha viária do país e grande prevalência de acidentes de trânsito (Diário de Campo, 2013).

A exemplo de outros hospitais de urgência, no território de observação pesquisado utilizam-se protocolos específicos no cuidado 25: (i) Escala de Coma de Glasgow: permite aferir e avaliar o nível de consciência, o que define a maior ou a menor gravidade e risco de morte; (ii) Protocolo de Manchester: estabelece critérios de gravidade que orientam o tempo de espera para o atendimento conforme o ris- 
co à vida; e (iii) Suporte Avançado de Vida no Trauma (SAVT): busca identificar as lesões graves e instituir medidas terapêuticas e emergenciais que restabeleçam a vida.

Quando as medidas mostram-se ineficazes, a morte do paciente traumatizado obedece a três picos de tempo 25: (i) Morte imediata: ocorre dentro de segundos a minutos após a injúria, devido à gravidade das lesões; (ii) Morte prematura: acontece dentro de minutos até várias horas após a injúria e representa a janela de oportunidade durante a qual a equipe médica pode ter impacto positivo na morbimortalidade; e (iii) Morte tardia: sobrevém entre vários dias a semanas após a injúria inicial. O cuidado dispensado aos pacientes durante cada uma das fases anteriores tem impacto sobre o prognóstico a longo prazo.

Assim, na cadeia de serviços que tangenciam esse perfil de cuidado, há uma variável importante denominada "hora de ouro", referente ao tempo entre o transporte do local do incidente até o atendimento definitivo, fundamental no prognóstico, na recuperação e no restabelecimento da vida 25. Outro dispositivo utilizado - presente no referido campo de estudo - é o heliponto, reservado ao transporte aéreo de pacientes com risco iminente de morte 26.

A instituição tem 440 leitos, sendo 130 de cuidados intensivos. Todo hospital com mais de 80 leitos conta com uma Comissão Intra-Hospitalar de Doação de Órgãos e Tecidos para Transplante, responsável por organizar e viabilizar o diagnóstico de morte encefálica; identificar possíveis doadores de órgãos e tecidos; oferecer suporte aos familiares destes pacientes; e articular-se com a Central de Transplante estadual 27. No presente caso, a captação e distribuição dos órgãos compete ao MG Transplantes, cuja sede está localizada no interior do próprio hospital.

Com cerca de 600 médicos, a população de estudo foi constituída por 43 médicos plantonistas 25 homens e 18 mulheres, entre 28 e 69 anos - que atuam em setores específicos para pacientes graves com risco de morte 24 .

\section{Coleta e análise dos dados}

A coleta dos dados foi realizada ao longo de nove meses de observação participante e entrevistas guiadas por roteiro semiestruturado. A seleção aconteceu pelo método "bola de neve" 28, sendo a amostra final regulada pelo critério de saturação 29.

A análise dos dados foi orientada pela corrente metodológica dos "signos, significados e ações" 23, que parte do horizonte pragmático dos indivíduos a fim de identificar e compreender as lógicas conceituais agregadas a suas ações, bem como os distintos fatores que as influenciam.

Para assegurar o anonimato, os entrevistados foram identificados, respectivamente, pela ordem da entrevista, especialidade médica, sexo (F para feminino, $M$ para masculino) e idade.

\section{Aspectos éticos}

Este estudo está em acordo com a Resolução no 466/2012 do Conselho Nacional de Saúde. Aprovado pelos comitês de ética da Universidade Federal de Minas Gerais (CAAE: 03751612.0.0000.5149) e da Fundação Hospitalar de Minas Gerais (SIPRO: 29128/2012-7).

\section{Resultados e discussão}

No trabalho de campo, verificou-se que o hospital pesquisado, de modo pioneiro no Brasil, tem dois leitos destinados à realização do protocolo para a confirmação ou não da morte cerebral e à definição da viabilidade de pacientes doadores de órgãos. Contudo, ao longo da etnografia foi possível compreender que tais funções, legitimadas e delegadas ao médico, extrapolam objetivos meramente técnicos e burocráticos.

Entre a constatação e a comunicação da morte emergem percepções ambivalentes dos profissionais que afetam direta e indiretamente a atuação médica, como será mostrado no item O Processo de Cuidado no Serviço de "Apoio à Vida", desdobrado conforme suas competências - apresentadas na forma de subcategorias. 


\section{O processo de cuidado no Serviço de "Apoio à Vida"}

Na maioria dos hospitais, o diagnóstico, a confirmação da morte encefálica e a identificação de potenciais doadores ocorre no CTI 8,10. Assim, a existência desse espaço peculiar gerou inquietações. À etnografia, ficou claro que, para além da atuação médica relativa ao momento da morte, suas funções adentram uma complexidade de elementos e relações imbricadas que não são passíveis de delimitações estanques nem foram apreendidas de forma temporal linear 24.

Nestes excertos, o próprio nome - Serviço de Apoio à Vida (SAV) - em tese, contrasta com um de seus propósitos: diagnosticar a morte encefálica:

"No SAV o doente já chega aqui mais para morto do que para vivo. Ele não está aqui para tratar, para ver se vai melhorar, ele vem para confirmar se está morto ou não” (E24, Cardiologia, M, 63 anos).

"É o doente sem nenhuma perspectiva, com uma lesão neurológica irreversível que vai morrer de qualquer jeito. Aí a gente faz os testes para ver se ele pode ser um doador de órgãos, antes que todos os órgãos morram (...). Cérebro morto é igual à morte; o coração ainda bate, mas daí a pouco ele vai parar de bater" (E25, Clínica Médica, F, 56 anos).

No Brasil, o Conselho Federal de Medicina (CFM) define a morte encefálica como a completa e irreversível interrupção das funções cerebrais que impossibilita a manutenção da vida sem o auxílio de meios artificiais 30 . Dois médicos explicam as funções do SAV:

"Documentar a morte encefálica e manter o paciente em condições adequadas do ponto de vista clínico e circulatório. Porque se for diagnosticada a morte encefálica e a família estiver de acordo ele é um doador de órgãos" (E24, Cardiologia, M, 63 anos).

"Definido [a doação], a gente liga para o MG Transplantes, que tem uma equipe mais capacitada com psicólogo e tudo, e eles que abordam essa parte de transplante” (E26, Clínica Médica, M, 32 anos).

O processo de cuidado no SAV responde ao cumprimento rigoroso de suas funções basilares exercidas e validadas pelo profissional de medicina: a garantia do cuidado intensivo ao paciente para estabelecer se é um potencial doador 6; a realização do protocolo de constatação da morte encefálica 10,31; e a comunicação do fato à família do paciente 7,32, como apresentado nas três subcategorias a seguir.

\section{- A garantia do cuidado intensivo ao paciente/potencial doador}

Um dos idealizadores da criação do SAV testemunha:

"Se nós só estivéssemos preocupados com a morte encefálica e não cuidarmos adequadamente desse paciente, na hora que der o diagnóstico não dá para você aproveitar nenhum órgão (...). É preciso ter uma unidade adequada para isso (...). O paciente, a partir do momento que perde o controle neurológico por morte encefálica, perde o controle de tudo: temperatura, circulação, respiração, e você tem que dar isso a ele de uma forma muito adequada (...). Os profissionais de outros setores não têm formação para fazer isso (...), ou seja, é uma adequação dos recursos às necessidades dos pacientes" (E24, Cardiologia, M, 63 anos).

Este clínico explica o dilema em outros serviços diante da necessidade de utilização de um leito de CTI para um paciente clinicamente não recuperável:

"Em outros hospitais é mais complicado (...). Estatisticamente, fora daqui eles conseguem um número pequeno [de doadores], porque é difícil ter um leito disponível para um doente desse e viabilizar isso sem um conhecimento técnico específico. Na maioria das vezes, o paciente acaba falecendo nas observações, nas salas de emergência, porque muitas vezes eles não deixam de ocupar esse leito de CTI, para um paciente, digamos potencialmente recuperável, para mandar um com suspeita de morte encefálica” (E27, Clínica Médica, M, 34 anos).

Assim, por cuidado intensivo no SAV, entende-se manter o paciente/potencial doador em condições hemodinâmicas favoráveis à doação de órgãos e tecidos após constatada a morte encefálica 15,18. Tal cuidado demanda aparatos humanos e técnicos, e o monitoramento constante e controlado de vários parâmetros vitais e sistemas fisiológicos 10,31, elemento crucial para possibilitar a doação de órgãos:

"Porque é um paciente sem prognóstico que muitas vezes é um doador e é uma pessoa que pode dar uma qualidade de vida para 6, 5 pessoas (...). Imagina uma pessoa que não enxerga voltar a enxergar com uma doação? Então o doente que está em morte encefálica, ele merece um cuidado especial, porque (...) só uma pessoa que recebe um órgão consegue descrever o que ê" (E18, Neurocirurgia, M, 34 anos). 
Nesse cuidado, são realizadas avaliações clínicas e laboratoriais para verificar e validar as condições do potencial doador, de modo a garantir qualidade e segurança para o processo de doação a partir da identificação de fatos e indícios de contraindicações, inclusive a presença de doenças infecciosas $6,15,18$.

Simultaneamente à garantia do melhor cuidado para esse doador, realiza-se o protocolo para a confirmação de uma possível morte encefálica.

\section{- O processo de confirmação da morte encefálica: o velório no leito}

De acordo com a Resolução no 2.173/2017 do CFM 30, para a constatação da morte encefálica são necessárias obrigatoriamente três condições clínicas simultâneas: coma não perceptivo, ausência de reflexos do tronco cerebral e apneia persistente (retirada do ventilador mecânico para a verificação da capacidade de respiração espontânea).

Uma vez suspeitada, aplica-se o Protocolo de Morte Encefálica, composto por testes clínicos realizados repetidamente em intervalos predeterminados, que servem para confirmar que o cérebro do potencial doador já não responde mais a estímulos 30 . Esse processo tem duração variável, como explica este profissional:

"Demora muito ou pouco. Para o paciente fazer os testes, depende de algumas condições: temperatura boa, (...) ions bons, condições hemodinâmicas e ventilatórias adequadas. Porque no teste tira o paciente do ventilador [mecânico] e deixa 10 minutos, para ver se ele respira. Então tem as condições mínimas. (...) Há pacientes que chegam pela manhã e à noite já estão com o diagnóstico definido de morte encefálica e há pacientes que ficam até 5 dias" (E26, Clínica Médica, M, 32 anos).

Talvez por isso, no período de realização do protocolo, pôde-se presenciar alguns familiares indagando ao médico: "E aí? Ele está bem hoje, doutor?", “Ontem ela estava meio caidinha, hoje ela está melhor?” (Diário de Campo, 2013). Dois profissionais explicam:

"Não podemos dizer que ele já 'morreu', temos que dizer sobre o óbito quando ele for decretado cientificamente, mesmo sabendo da sua quase certeza" (E24, Cardiologia, M, 63 anos).

“Às vezes é um luto prolongado que começa aqui com o paciente 'quase-morto, ainda vivo', que a família sabe que vai morrer e fica sofrendo porque a gente não consegue fechar o protocolo. É um velório com o paciente ainda vivo, pois liberamos a família para ficar junto do enfermo” (E26, Clínica Médica, M, 32 anos).

A presença do familiar pode ajudar na sua compreensão do processo de morte encefálica 12,13. Porém, apesar de a morte cerebral ser ratificada somente após o cumprimento estrito do protocolo, ao longo deste percurso já se observa um processo de luto e negação dos familiares. Pesquisas internacionais 12,13 consideram que as famílias devem ter a opção de estar presente nesse momento, porém, poucas unidades oferecem tal alternativa ${ }^{12}$. Isso requer o desenvolvimento de diretrizes que envolvam os profissionais, a fim de proporcionar excelência em cuidados no fim da vida.

Esse paciente híbrido - "vivo e morto ao mesmo tempo" - encontra-se em um estado de fronteira: um corpo morto inserido num corpo vivo, que não possui - ou possui pouco - os atributos do passado ou do futuro ${ }^{33}$. Nessa perspectiva, Le Breton 33 reconhece que com o cérebro inerte o homem se desvanece, mas a morte latente não consegue alterar sua face ou seu corpo. Ninguém saberia dizer onde ele está, se em vida ou em morte, se presente ou ausente, e mesmo os parentes desconhecem se devem continuar a ter esperanças ou se já devem chorar.

Essa ambiguidade refere-se, necessariamente, à condição de não pertencimento à rede de classificações convencionais que definem a localização de estados e posições num espaço cultural 33, e contribui para a dificuldade dos profissionais diante desses pacientes, principalmente quando apresentam o reflexo de Lázaro. Dois médicos reconhecem:

"A enfermagem assusta muito, acha que o paciente está vivo e tenta ligar os aparelhos, dai a gente tem que explicar que são apenas reflexos, que o paciente já está morto” (E28, Terapia Intensiva, F, 49 anos).

"É um reflexo medular, aquele mesmo da Bíblia. (...) Você está no horário de visitas, o familiar diz: 'ah, ele está quentinho', aí a pessoa põe a mão nele e o pé levanta. Mas ele não está vivo, está em morte encefálica. Para a doação essa questão é muito mais difícil, porque para o familiar, se o doente for doador, fica parecendo que a gente está matando o paciente, porque as pessoas pensam que ele não está morto" (E26, Clínica Médica, M, 32 anos).

Cabe ao médico balizar elementos que se tencionam ao longo do cuidado ao paciente em suspeita de morte encefálica. Comumente, durante o teste de apneia, o paciente subitamente levanta ambos os 
braços e os coloca sobre o tórax. Em outros casos, pode ocorrer a flexão total do tronco e o paciente sentar-se na cama, resultando na contração de toda a musculatura (Diário de Campo, 2013). Embora dramático para quem observa e catalisador para a não aceitação do óbito quando ele ocorre, tais reflexos não inviabilizam o diagnóstico final da morte encefálica, sendo necessário desmitificá-los para evitar atrasos no protocolo e falsas interpretações 10,34.

Confirmada a morte cerebral, a terceira função do SAV é comunicá-la aos familiares e abordar a possibilidade de doação de órgãos.

\section{- A comunicação da morte encefálica e a abordagem da família para a doação de órgãos}

Toda comunicação inclui a mensagem, o contexto e os interlocutores envolvidos.

Este profissional expõe suas dificuldades no processo de comunicação da morte encefálica:

"A relação com os familiares às vezes é difícil, pois eles tendem a negar: racionalizam e negam ao mesmo tempo. Na hora da visita no $S A V$, você explica que o paciente não vai andar, não vai conversar, que só por um milagre ele vai se recuperar. Você fica uns 20 minutos falando da gravidade. Eu só não tiro a esperança. Tem gente que fala 'olha, meus sentimentos, ele está morto, nós só estamos aguardando para definir com os exames'. Eu não, eu gosto de conversar, ai no final da conversa depois de explicar mil coisas, a pessoa pergunta: 'Mas e aí, doutor? Daqui a uns dias ele vai embora para casa?'. Parece que o parente não ouviu nada do que você falou, ele nega totalmente" (E26, Clínica Médica, M, 32 anos).

Comunicar o óbito é a parte fundamental da assistência dada ao paciente e a seus familiares 9 , porém, revela-se uma tarefa complexa para a qual o médico não se vê preparado 7,32 . Nesse caso, a dificuldade na comunicação ainda é potencializada por diferentes signos agrupados em seus respectivos significados: as controvérsias na definição da morte encefálica, o contexto sociocultural e o contexto do pronto-atendimento (Quadro 1).

Quanto às controvérsias na definição da morte encefálica (Quadro 1), os entrevistados discorrem sobre as dificuldades que envolvem "uma função vital artificial" e levam à negação e incompreensão por profissionais e familiares. Embora a morte do cérebro seja clínica e legalmente reconhecida, há um desacordo do seu significado entre médicos, filósofos e outros atores diretamente envolvidos 16 . Estudos 16,35,36 consideram que, desde a sua criação, esse conceito expõe controvérsias acerca da sua validade e coerência, sobretudo sua equivalência à definição de morte tradicionalmente aceita, vinculada à parada cardiorrespiratória.

Na sociedade ocidental, o conceito de morte biológica passou por várias definições. Até a Renascença pensava-se que o controle do corpo era realizado pelo coração 36. A partir do século XIX, foram identificados três órgãos responsáveis pela manutenção da vida: o coração, os pulmões e o cérebro, os quais estariam de tal modo interligados que a morte ou falência de um implicaria a dos demais 9,21. E, embora o termo morte encefálica tenha surgido em 1959 na França, até a década de 1960, o único critério médico para a constatação da morte era a parada cardiorrespiratória. Apenas em 1967, com a realização do primeiro transplante de coração humano, retomaram-se as discussões sobre o conceito de morte clínica 21,36

Essa "nova morte", como definida por Macedo 21, somente foi viabilizada porque existe um contexto social singular que contempla ciência, tecnologia, medicina e modernidade. Todavia, cria-se uma linha tênue entre corpo e máquina, natureza e cultura, vida e morte, alicerçada, sobretudo, pelo advento de novas tecnologias biomédicas 21 . Tais avanços reforçam a noção do corpo humano compreendido como máquina e submetido à lógica do saber biomédico, restrito a um grupo de especialistas e protegido pela racionalidade de seus discursos 33 .

Por sua vez, o contexto sociocultural (Quadro 1) é atravessado por aspectos religiosos e de configurações específicas a cada cultura 12,26, que revelam uma diversidade de comportamentos e compreensões acerca da morte. Na sociedade brasileira, caracterizada por uma pluralidade de crenças e sob forte influência cristã, o apelo religioso está vinculado à esperança da reversão do quadro mediada por um milagre divino que faça o paciente voltar a viver 37 . Assim, o médico não consegue demover os familiares da vontade de lutar pela vida de seus entes 26 .

Outrossim, é importante demarcar que a morte encefálica sobrevém no contexto do pronto-atendimento (Quadro 1), cujas características de cuidado representam fatores limitantes para a atuação médica e a comunicação com a família. Dentre eles, ressaltam-se o fato de se tratar de uma morte 


\section{Quadro 1}

Os signos e os significados envolvidos na comunicação da morte encefálica.

\begin{tabular}{|c|c|}
\hline SIGNOS & SIGNIFICADOS \\
\hline $\begin{array}{l}\text { "Eu tenho mais dificuldade de dar notícia quando ele está em morte cerebral do que quando ele morre. (...) O } \\
\text { paciente morreu, mas o coração está batendo e ele vai morrer. Esse é o mais difícil para você abordar a } \\
\text { família. Não é que é difícil explicar, mas é que a agonia que a família entra (...) porque o que é a morte cerebral? } \\
\text { O conceito? O que é morte? É a cessação das funções vitais, mas o paciente em morte cerebral tem função vital } \\
\text { artificial" (E19, Neurocirurgia, M, } 32 \text { anos). }\end{array}$ & \multirow{2}{*}{$\begin{array}{l}\text { Controvérsias na definição da } \\
\text { morte encefálica }\end{array}$} \\
\hline $\begin{array}{l}\text { "Eu acho que ainda tem um medo, um misticismo em volta disso e uma negação, principalmente nas experiências } \\
\text { que eu tive com morte encefálica. Eles [os familiares] não entendem. A morte está muito ligada com a parada do } \\
\text { coração. A pessoa vê que o coração está batendo, mas não entende que o cérebro está morto, que não tem como } \\
\text { a pessoa viver" (E42, Clínica Médica, F, } 28 \text { anos). }\end{array}$ & \\
\hline $\begin{array}{l}\text { "O Brasil é um país com uma raiz católica muito grande. O catolicismo por si só tem uma dificuldade muito } \\
\text { grande para lidar com a morte, e o brasileiro mais ainda, por ter esse sangue latino, então a gente é muito } \\
\text { passional. Eu fiquei um tempo no exterior (...) e lá é surpreendente. Você falava 'morreu', o anglo-saxão é frio. } \\
\text { Então quando tinha um doente grave canadense, americano, inglês, vinha uma pessoa para receber a notícia, } \\
\text { totalmente equilibrada para passar a notícia para frente. Quando era um paciente latino, sul-americano vinham } \\
300 \text { familiares. Quando você falava que o doente estava grave, meia dúzia caía no chão, era aquela gritaria. Então } \\
\text { é muito diferente" (E19, Neurocirurgia, M, } 32 \text { anos). }\end{array}$ & \multirow[t]{2}{*}{ Contexto sociocultural } \\
\hline $\begin{array}{l}\text { "Teve um menino que fez uma cirurgia cardíaca e depois teve uma complicação e entrou em morte encefálica, e o } \\
\text { pai dele era um pediatra japonês. O pai dele ficou de pé ao lado dele uns } 3 \text { dias, em pé de braço cruzado, igual a } \\
\text { uma imagem de samurai. Ele não deu uma palavra, não falou nada com ninguém, não reclamou. Isso foi uma } \\
\text { das coisas que me impressionou demais e eu vi muita gente despreparada para lidar com isso, eu vi vários tipos de } \\
\text { manifestação sempre quando envolve gente muito jovem, no final das contas a gente vê muitas cenas grotescas, } \\
\text { um misto de dor, não aceitação" (E1, Cirurgia Cardiovascular, M, } 53 \text { anos). }\end{array}$ & \\
\hline $\begin{array}{l}\text { "Aqui, por a gente lidar com uma pessoa que há um minuto estava bem e daqui um minuto está à frente } \\
\text { da morte, os familiares não estão preparados para aceitar isso. Diferente de um hospital que a gente trata de } \\
\text { pacientes cancerosos, crônicos, que já se absorveu a ideia de morte (...). Então ninguém está preparado, no caso } \\
\text { a família, para receber esse tipo de notícia" (E15, Neurocirurgia, M, } 40 \text { anos). }\end{array}$ & \multirow{3}{*}{$\begin{array}{l}\text { Contexto do pronto- } \\
\text { atendimento }\end{array}$} \\
\hline $\begin{array}{l}\text { "O SAV é o principal lugar onde a família nega a morte, porque olha só: você vê o seu familiar pela manhã e à } \\
\text { tarde alguém te liga. Você vem para o hospital e fica sabendo que ele não vai viver mais. E tem alguns pacientes } \\
\text { que ficam no SAV, cujo trauma que o lesou não machuca muito externamente, só machuca internamente. Então o } \\
\text { paciente não tem um arranhão, parece que está dormindo" (E26, Clínica Médica, M, } 32 \text { anos). }\end{array}$ & \\
\hline $\begin{array}{c}\text { "Eu acho que ninguém nunca está preparado, principalmente se é algo abrupto como o trauma. Ninguém } \\
\text { na sociedade está preparado para perder um parente, alguém que gosta, de um modo abrupto" (E5, } \\
\text { Anestesiologia, F, } 32 \text { anos). }\end{array}$ & \\
\hline
\end{tabular}

SAV: Serviço de Apoio à Vida.

inesperada e abrupta para a qual ninguém está preparado. Nesse contexto de atuação, inexiste um relacionamento prévio do médico com o paciente e sua família, e falta-lhe tempo para dedicar-se exclusivamente a cada um, devido às múltiplas e urgentes demandas dos demais 24,38,39.

A comunicação da morte encefálica antevê dois desfechos: o primeiro, o paciente/potencial doador nesta condição morrerá; o segundo, por meio da sua morte e doação de órgãos ele pode favorecer e prolongar a vida de outras pessoas 14,17 . Nesse sentido, a compreensão do que seja a morte e a vida pode variar, a depender do desejo do familiar de que o paciente/potencial doador sobreviva e, portanto, a doação não se cumpra; ou o contrário, de que ele sobreviva por meio da doação de órgãos para outras pessoas, como traduz este relato:

"Na época que nós criamos esses leitos para o protocolo da morte encefálica, tinha acontecido uma situação em São Paulo em que eles pegaram um doador e o pai chegou na televisão e falou: 'infelizmente eles cuidaram 
do meu filho melhor na morte do que quando ele estava vivo ainda'. Um dia eu recebi várias mensagens de um suposto paciente que falava assim: 'Estou aqui no CTI [da instituição] em morte encefálica. Eu já morri e quero doar os meus órgãos (...)'. Daí eu liguei para cá e perguntei o que estava acontecendo. Eles disseram que o cara estava completamente em sepse, sem a menor condição de doar e uma pessoa que teve um relacionamento com ele (...) quer porque quer que ele doe órgãos, porque seria uma forma dele sobreviver. Aí eu vi como o transplante pode ser interpretado de uma forma louca. (...) A vida continua de alguma forma, a linha da vida continua, mas a pessoa não continua. Então, é muito difícil" (E1, Cirurgia Cardiovascular, M, 53 anos).

Quando o médico valida o paciente como potencial doador, ainda assim a doação pode não ocorrer caso o paciente, embora preencha os critérios, tenha optado em vida pela não-doação ou a família recuse a doação 15,19,20. Nesse último caso, os principais motivos envolvem: receio de mutilação e desejo da manutenção do corpo íntegro, por considerá-lo sagrado e intocável; desconfiança sobre a licitude do processo de doação; convicção religiosa; demora na liberação do corpo (realização do protocolo); desconhecimento do desejo do doador; insatisfação com a abordagem realizada pela equipe $15,19,20$.

Embora o diagnóstico de morte encefálica deva ser realizado somente por médicos especializados - intensivista, neurologista ou neurocirurgião - e experientes, isto é insuficiente para garantir a análise abrangente da situação do indivíduo e a abordagem adequada dos familiares 8,35. Faz-se necessário aliar as diretrizes técnicas do conceito de morte encefálica e as variações socioculturais dos atores envolvidos no processo ${ }^{12}$.

Nota-se uma dubiedade de sentidos acerca do conceito de morte encefálica, a depender do ator envolvido no processo:

"A morte no SAV para o médico é sempre mais tranquila, porque o paciente já chega aqui sem prognóstico. Nada que eu fizer vai mudar o desfecho final que é a morte. Já para a familia é sempre pior, pois geralmente são pacientes que saíram de manhã para trabalhar e de repente está morto” (E26, Clínica Médica, M, 32 anos).

Quando o paciente em morte encefálica não pode ser doador, seja por razões técnicas, pessoais ou familiares, o médico está amparado por respaldos legal e ético a desligar os aparelhos 40. Esta profissional pontua:

"Esse momento é muito difícil, porque às vezes demora muito entre você desligar o respirador e o coração parar de bater. Já aconteceu comigo de demorar 27 minutos. Eu desligo e sento do lado e fico lá, olhando para o monitor, com a mão no pulso do paciente. Parece que é o instinto vital do paciente insistindo para que ele não morra. (...) Há profissionais que desligam todos os aparelhos de uma vez. Eu não. Enquanto há sinais vitais consideráveis, eu vou diminuindo aos poucos, isso me ameniza. Fica uma morte mais suave, e não abruptamente concretizada" (E28, Terapia Intensiva, F, 49 anos).

Embora, do ponto de vista técnico, para os médicos a morte encefálica seja a "mais tranquila" de lidar, a entrevistada revela sua angústia diante da espera pela consumação de um óbito que ela sabia certo e evidencia as dificuldades do saber biomédico em lidar com a morte e o morrer ${ }^{4}$.

Caso seja doador, depois de concluído o protocolo a família é comunicada e, concordando, a doação de órgãos é cumprida. O paciente/potencial doador é encaminhado ao bloco cirúrgico com o coração ainda batendo para a retirada dos órgãos. Um médico esclarece:

"O momento da morte é quando finaliza o protocolo. Definimos o horário após cumprir todos os exames prescritos ainda aqui no SAV. Tem outra questão: como poderíamos definir a morte de um corpo sem todos os seus órgãos, com seus órgãos incompletos?!” (E26, Clínica Médica, M, 32 anos).

Segundo o profissional, caso o horário da morte fosse atestado após a retirada dos órgãos não se caracterizaria e atestaria a morte de um corpo. Os entrevistados não demonstraram dificuldades ou dúvidas em determinar o horário legal do óbito, o que contrasta com outro estudo no qual a maioria dos participantes considerou como horário do óbito o momento de abertura do protocolo de morte encefálica ou da retirada de órgãos 9 .

Assim, embora a morte seja um evento recorrente no cotidiano profissional, ela assume nuances e contornos distintos, a depender de suas circunstâncias e dos conceitos de vida e de morte 4,7,26. Como todo fenômeno social de caráter totalizante 4 , essas definições extrapolam a dimensão biológica e envolvem dinâmicas socioculturais específicas, o que reverbera na experiência vivida pelo indivíduo 26. O cuidado médico é atravessado por questões culturais que permeiam a compreensão do processo de saúde/adoecimento entre profissionais e usuários. Nesse movimento, são identificadas interações fora e entre os indivíduos, e o que se manifesta é a vida cotidiana em ato 11,24,26. 
Na perspectiva de uma síntese, propõe-se um diagrama esquemático (Figura 1) que visa a integrar os diferentes elementos que orientam o processo de cuidado médico ao paciente grave com suspeita de morte encefálica em um serviço de pronto-atendimento, para além do cuidado intensivo, da realização do protocolo e da comunicação com a família.

Sem pretender esgotar toda a complexidade dos fenômenos estudados, diferentemente dos outros cenários de atuação médica identificados e investigados na etnografia 24,26, a morte encefálica provoca reações distintas, a depender do desfecho final do cuidado. O dilema doação/não-doação num contexto sociocultural e de um pronto-atendimento encobre as dificuldades do médico em lidar com a morte encefálica e em comunicá-la, dadas as controvérsias desse conceito. Somam-se a isso os conflitos teóricos entre o prognóstico (o paciente está morrendo) e o diagnóstico (o paciente está morto) nesse tipo de morte 35 .

Para Macedo 21, conflitos éticos que englobam questões acerca de certo "caráter utilitário" da morte encefálica também atravessam esse conceito. É como se o processo de confirmação desse tipo de morte pudesse ser comparado a um jogo com regras e fases específicas, no qual o desfecho de cada uma definirá a seguinte, considerando-se vitorioso quando culminar na doação de órgãos.

No universo pesquisado, ao final desse processo, foi possível observar a frustração do profissional quando a família não permite a doação de órgãos e o óbito ocorre sem que haja o restabelecimento de vidas. Porém, quando há a concordância da família, percebe-se uma sensação de êxito da atuação

\section{Figura 1}

Elementos que orientam o processo de cuidado médico ao paciente com suspeita de morte encefálica e potencial doador.

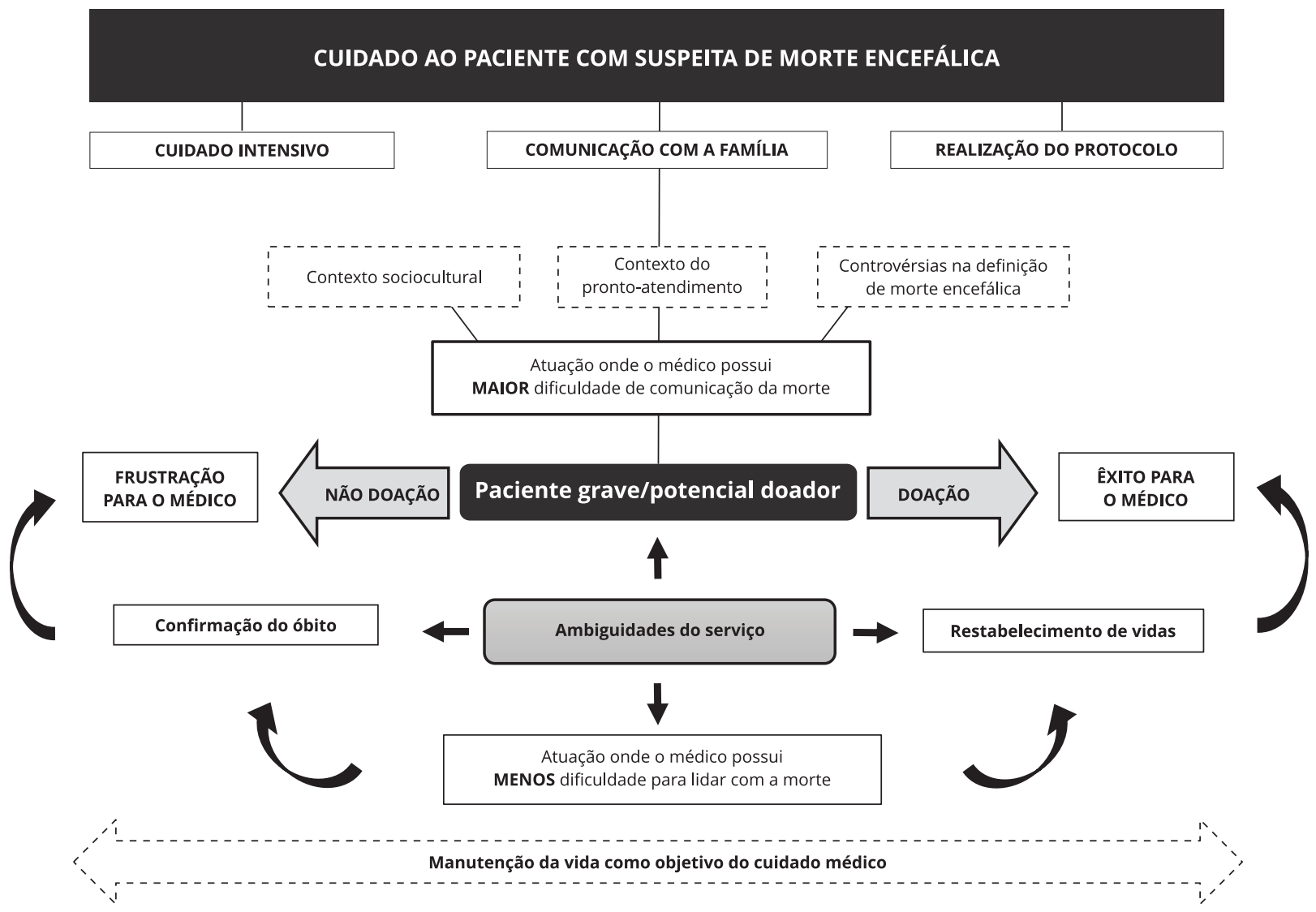


médica, pois a morte daquela pessoa de algum modo foi suplantada na vida que seus órgãos carreiam e continuam em outras histórias de vida. Como bem colocado por Macedo 21, a morte encefálica seria uma forma de "matar a morte" no campo médico.

Por outro lado, como já confirmado em outros estudos 24,26, seja qual for o setor de atuação médica no pronto-atendimento, nota-se latente ou manifesta a estrutura institucional biomédica, na qual a luta pela manutenção da vida se confunde com o cuidado 24,26. Assim, no cuidado a um paciente grave com suspeita de morte encefálica, o que vai tornar esse processo de morte menos difícil para o profissional é o seu contato ainda tênue com a vida manifesta no corpo, a qual se esvai lentamente, mas guarda o potencial de auxiliar a manter outras vidas concretizado na doação de órgãos. Mesmo num local onde a morte é tangível, o saber biomédico persiste em busca da manutenção da vida como propósito basilar da atuação médica.

\section{Considerações finais}

No último século, a expansão de novas tecnologias biomédicas de suporte cardíaco e ventilação mecânica possibilitou o prolongamento da vida, inclusive de pacientes com morte encefálica. Por sua vez, essa nova condição de morte propiciou a doação de órgãos e a continuidade da vida.

Nesta etnografia, nota-se que o processo de cuidado médico ao paciente em suspeita de morte encefálica ultrapassa questões normativas e envolve, sobretudo, o papel do profissional como mediador de uma miríade de elementos e tensões imbricados. Embora seja um conceito definido e legitimado, na prática ele adquire interpretações controversas: a definição, a constatação e a comunicação da morte encefálica envolvem percepções ambivalentes dos profissionais e dos familiares.

Dada a complexidade da questão, sem desmerecer os limites e angústias do cuidado ao paciente vítima de morte encefálica, na formulação de políticas públicas na área da saúde a capacitação das equipes médicas quanto à morte encefálica não deve se restringir à legitimação do óbito e às melhorias nos índices de doação. Ela precisa estar associada às concepções dos indivíduos acerca dos significados de vida e de morte, no seu contexto sociocultural. Isso inclui compreender os sentidos elaborados pelo próprio médico, que repercutem no cuidado ao paciente/potencial doador e aos familiares.

\section{Colaboradores}

J. S. Aredes trabalhou na concepção e planejamento do projeto, coleta, análise e interpretação dos dados; contribuiu na elaboração e redação do artigo e na revisão crítica relevante do conteúdo intelectual; participou da aprovação da versão final do manuscrito, sendo responsável por todos os aspectos do trabalho. J. O. A. Firmo e K. C. Giacomin trabalharam na concepção e planejamento do projeto, análise e interpretação dos dados; contribuíram na elaboração e redação do artigo e na revisão crítica relevante do conteúdo intelectual; participaram da aprovação da versão final do manuscrito, sendo responsáveis por todos os aspectos do trabalho.

\section{Agradecimentos}

À Coordenação de Aperfeiçoamento de Pessoal de Nível Superior (Capes - bolsa de doutorado) e ao Conselho Nacional de Desenvolvimento Científico e Tecnológico ( $\mathrm{CNPq}$ - bolsa de produtividade, processo 303372/2014-1). 


\section{Referências}

1. Pessôa LR, Santos IS, Machado JP, Martins ACM, Lima CRA. Realocar a oferta do SUS para atender problemas do futuro: caso do trauma no Brasil. Saúde Debate 2016; 40:9-19.

2. Diniz EPH, Pinheiro LC, Proietti FA. Quando e onde se acidentam e morrem os motociclistas em Belo Horizonte, Minas Gerais, Brasil. Cad Saúde Pública 2015; 31:2621-34.

3. Coelho MF, Goulart BF, Chaves LDP. Urgências clínicas: perfil de atendimentos hospitalares. Rev Rene (Online) 2013; 14:50-9.

4. Aredes JS, Modesto AL. "Entre vidas e mortes, entre máscaras e fugas”: um estudo sobre a prática médica hospitalar. Physis (Rio J.) 2016; 26:435-53.

5. O'Dwyer G, Konder MT, Reciputti LP, Macedo C, Lopes MGM. O processo de implantação do Serviço de Atendimento Móvel de Urgência no Brasil: estratégias de ação e dimensões estruturais. Cad Saúde Pública 2017; 33:e00043716.

6. Magalhães ALP, Lanzoni GMM, Knihs NS, Silva EL, Erdmann AL. Segurança do paciente no processo de doação e transplante de órgãos e tecidos. Cogitare Enferm 2017; 22:e45621.

7. Monteiro DT, Reis CGC, Quintana AM, Mendes JMR. Morte: o difícil desfecho a ser comunicado pelos médicos. Estud Pesqui Psicol 2015; 15:547-67.

8. Moraes EL, Neves FF, Santos MJ, Merighi MAB, Massarollo MCKB. Experiências e expectativas de enfermeiros no cuidado ao doador de órgãos e à sua família. Rev Esc Enferm USP 2015; 49(Esp 2):129-35.

9. Magalhães JV, Veras KN, Mendes CMM. Avaliação do conhecimento de médicos intensivistas de Teresina sobre morte encefálica. Rev Bioét 2016; 24:156-64.

10. Westphal GA. Diretrizes para avaliação e validação do potencial doador de órgãos em morte encefálica. Rev Bras Ter Intensiva 2016; 28:220-55.

11. Ayres JRCM. Cuidado: trabalho e interação nas práticas de saúde. Rio de Janeiro: Centro de Estudos e Pesquisa em Saúde Coletiva, Instituto de Medicina Social, Universidade do Estado do Rio de Janeiro/Abrasco; 2011.

12. Doran M, Black P. Seeing for themselves healthcare professionals' views about the presence of family members during brainstem death testing. J Clin Nurs 2017; 26:1597-607.

13. Tawil I, Brown LH, Comfort D, Crandall CS, West SD, Rollstin AD, et al. Family presence during brain death evaluation: a randomized controlled trial. Crit Care Med 2014; 42:934-42.

14. Escudero D, Otero J. Intensive care medicine and organ donation: exploring the last frontiers? Med Intensiva 2015; 39:373-81.

15. Birtan D, Arslantas MK, Dincer PC, Altun GT, Bilgili B, Ucar FB, et al. Effect of interviews done by intensive care physicians on organ donation. Transplant Proc 2017; 49:396-8.

16. Johnson LS. The case for reasonable accommodation of conscientious objections to declarations of brain death. J Bioeth Inq 2016; 13:105-15.
17. Camut S, Baumann A, Dubois V, Ducrocq X, Audibert G. Non-therapeutic intensive care for organ donation: a healthcare professionals' opinion survey. Nurs Ethics 2016; 23:191-202.

18. Cisne MSV, Netto JM, Santos TC, Brito MC, Soares JSA, Goyanna NT. Percepção de acadêmicos de enfermagem e medicina sobre fragilidades na atenção ao potencial doador de órgãos. Rev Enferm Atenção Saúde 2016; 5:64-73.

19. Barreto BS, Santana RJB, Nogueira EC, Fernandez BO, Brito FPG. Fatores relacionados a não doação de órgãos de potenciais doadores no Estado de Sergipe, Brasil. Rev Bras Pesqui Saúde 2016; 18:40-8

20. Maynard LOD. Os conflitos do consentimento acerca da doação de órgãos post mortem no Brasil. Rev Direito Sanit 2016; 16:122-44.

21. Macedo JL. As regras do jogo da morte encefálica. Rev Antropol (São Paulo) 2016; 59:32-58.

22. Geertz C. A interpretação das culturas. Rio de Janeiro: LTC; 1989.

23. Corin E, Uchôa E, Bibeau G, Koumare B. Articulation et variations des systèmes de signes, de sens et d'actions. Psychopathol Afr 1992; 24:183-204.

24. Aredes JS, Firmo JOA, Leibing A, Giacomin KC. Reflexões sobre um fazer etnográfico no pronto-socorro. Cad Saúde Pública 2017; 33:e00118016.

25. American College of Surgeons. ATLS - Advanced Trauma Life Support: student course manual. 9th Ed. Chicago: American College of Surgeons; 2012.

26. Aredes JS, Giacomin KC, Firmo JOA. O médico diante da morte no pronto-socorro. Rev Saúde Pública 2018; 52:42.

27. Ministério da Saúde. Portaria no 1.752 , de 23 de setembro de 2005. Determina a constituição de Comissão Intra-Hospitalar de Doação de Órgãos e Tecidos. Diário Oficial da União 2005; 24 set.

28. Patton MQ. Qualitative research and evaluation methods. London: Sage Publications; 2002.

29. Fontanella BJB, Luchesi BM, Saidel MGB, Ricas J, Turato ER, Melo DG. Amostragem em pesquisas qualitativas: proposta de procedimentos para constatar saturação teórica. Cad Saúde Pública 2011; 27:389-94.

30. Conselho Federal de Medicina. Resolução CFM no 2.173, de 23 de novembro de 2017. Define os critérios do diagnóstico de morte encefálica. Diário Oficial da União 2017; 15 dez.

31. Rodrigues SLL, Ferraz Neto JBE, Sardinha LAC, Araújo S, Zambelli HJL, Boin IFSF, et al. Perfil de doadores efetivos do serviço de procura de órgãos e tecidos. Rev Bras Ter Intensiva $2014 ; 26: 21-7$.

32. Stelet BP, Castiel LD, Moraes DR. Anomalisa e o ensino da comunicação clínica na prática médica. Cad Saúde Pública 2017; 33:e00154016. 
33. Le Breton D. A síndrome de Frankenstein. In: Santana DB, organizador. Políticas do corpo: elementos para uma história das práticas corporais. São Paulo: Estação Liberdade; 1995. p. 49-67.

34. Morato EG, Resende MT, Trivelato FP, Pimenta NG, Maluf FB, Leão ADG, et al. "Sinal de Lázaro”: reflexo medular complexo na morte encefálica - relato de dois casos. Rev Méd Minas Gerais 2009; 19:253-7.

35. Rodrigues CFA, Stychnicki AS, Boccalon B, Cezar GS. Morte encefálica, uma certeza? O conceito de "morte cerebral" como critério de morte. Bioethikos 2013; 7:271-81.

36. Rodrigues Filho EM, Junges JR. Morte encefálica: uma discussão encerrada? Rev Bioét 2015; 23:485-94.

37. Xavier MS, Miziara CSMG, Miziara ID. Terminalidade da vida: questões éticas e religiosas sobre a ortotanásia. Saúde, Ética \& Justiça 2014; 19:26-34.
38. Lamba S, Nagurka R, Offin M, Scott SR. Structured communication: teaching delivery of difficult news with simulated resuscitations in an Emergency Medicine Clerkship. West J Emerg Med 2015; 16:344-52.

39. Reyniers T, Houttekier D, Cohen J, Pasman HR, Deliens L. The acute hospital setting as a place of death and final care: a qualitative study on perspectives of family physicians, nurses and family carers. Health Place 2014; 27:77-83.

40. Conselho Federal de Medicina. Resolução CFM no 1.826/2007, de 24 de outubro de 2007. Dispõe sobre a legalidade e o caráter ético da suspensão dos procedimentos de suportes terapêuticos quando da determinação de morte encefálica de indivíduo não-doador. Diário Oficial da União 2007; 6 dez. 


\section{Abstract}

The objective of this study was to understand how physicians at the largest emergency department in a large Brazilian city orient care for critical patients with suspected brain death and who are potential organ donors. This ethnographic study was conducted in an emergency care hospital, a reference in traumatology in Latin America, located in downtown Belo Horizonte, Minas Gerais State. The institution took pioneering steps in Brazil with a specific sector where patients with suspected brain death are referred. The fieldwork was performed over the course of nine months, based on targeted observations and interviews with 43 on-duty staff physicians ( 25 men and 18 women), from 28 and 69 years of age. Data analysis followed the "signs, meanings, and actions" model. The ethnography revealed the process of medical care for patients with suspected brain death, including: intensive care, adherence to protocol, and communicating the patient's status to the family. In the latter case, the dialogue reveals the controversies in the concept of brain death, the sociocultural context, and the emergency care context. It became clear that this process of medical care extrapolates merely normative issues, entering into a complex web of elements, especially the professional's role as mediator of a myriad of interwoven elements and tensions. Between confirmation of the brain death and communicating the situation to the family, ambivalent perceptions emerge, both for the physicians and the family members. The study evidenced how the tenuous definition of what constitutes life and death touches on all of the medical act, with direct implications on care for patients/potential donors and their families.

Brain Death; Attitude to Death; ProfessionalFamily Relations; Emergency Medicine; Delivery of Health Care

\section{Resumen}

El objetivo de este trabajo es comprender cómo los médicos del mayor servicio de urgencias de una metrópoli brasileña orientan en el cuidado a pacientes graves, con sospecha de muerte encefálica, $y$ potenciales donadores de órganos. Se trata de un trabajo etnográfico, desarrollado en un hospital con servicio de urgencias, referente en casos de trauma en Latinoamérica, situado en la zona metropolitana de Belo Horizonte, Minas Gerais. La institución, de modo pionero en Brasil, cuenta con un sector específico, donde se dirigen los pacientes con sospecha de muerte encefálica. El trabajo de campo se realizó durante nueve meses, basado en observaciones empíricas y entrevistas, junto a 43 médicos de guardia - 25 hombres y 18 mujeres-, entre 28 y 69 años. El análisis de los datos se orientó por el modelo de "signos, significados y acciones". Con la etnografía, emergió el proceso de cuidado médico al paciente con sospecha de muerte encefálica que contempla: terapia intensiva, realización del protocolo y comunicación del hecho a la familia del paciente. En ese último caso, la interlocución revela las controversias en el concepto de muerte encefálica, contexto sociocultural y contexto del servicio de urgencias. Quedó claro que este proceso de cuidado médico ultrapasa cuestiones meramente normativas y se adentra en una complejidad de elementos, sobre todo respecto al papel del profesional como mediador de una miríada de elementos y tensiones imbricados. Entre la constatación y la comunicación de la muerte encefálica emergen percepciones ambivalentes de médicos y familiares. El estudio evidenció que la tenue definición de lo que es vida y muerte es tangencial a toda la actuación médica, teniendo implicaciones directas en el cuidado al paciente/potencial donador y para los familiares.

Muerte Encefálica; Actitud Frente a la Muerte; Relaciones Profesional-Familia; Medicina de Emergencia; Prestación de Atención de Salud
Recebido em 26/Mar/2018

Versão final reapresentada em 25/Mai/2018

Aprovado em 12/Jul/2018 